\title{
Effect of Solution pH on the Dual Role of Dissolved Organic Matter in Sensitized Pollutant Photooxidation
}

\author{
Jannis Wenk,* Cornelia Graf, Michael Aeschbacher, Michael Sander, and Silvio Canonica* \\ Cite This: Environ. Sci. Technol. 2021, 55, 15110-15122 \\ Read Online
}

ACCESS 1

Wll Metrics \& More

Article Recommendations

Supporting Information

ABSTRACT: Dissolved organic matter (DOM) has a dual role in indirect phototransformations of aquatic contaminants by acting both as a photosensitizer and an inhibitor. Herein, the $\mathrm{pH}$ dependence of the inhibitory effect of DOM and the underlying mechanisms were studied in more than 400 kinetic irradiation experiments over the $\mathrm{pH}$ range of 6-11. Experiments employed various combinations of one of three DOM isolates, one of two model photosensitizers, the model antioxidant phenol, and one of nine target compounds (TCs), comprising several aromatic amines, in particular anilines and sulfonamides, and 4-cyanophenol. Using model photosensitizers without antioxidants, the phototransformation of most TCs increased with increasing $\mathrm{pH}$, even for TCs for

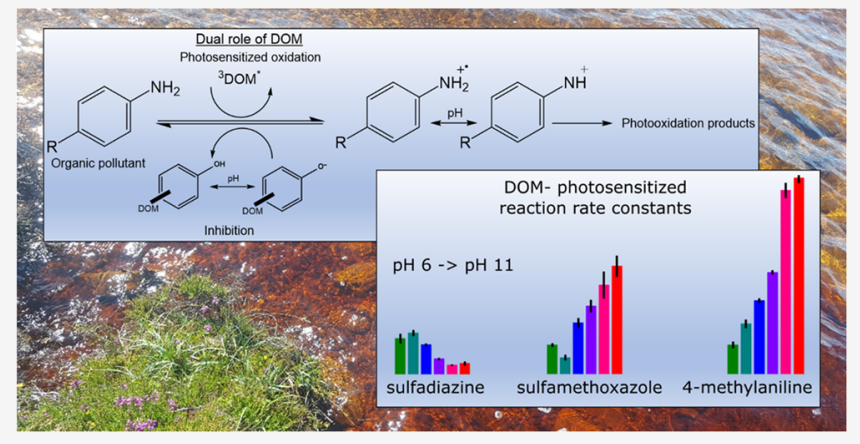
which $\mathrm{pH}$ did not affect speciation. This trend was attributed to $\mathrm{pH}$-dependent formation yields of TC-derived radicals and their reformation to the parent TC. Analogous trends were observed with DOM as a photosensitizer. Comparison of model and DOM photosensitizer data sets showed increasing inhibitory effects of DOM on TC phototransformation kinetics with increasing $\mathrm{pH}$. In systems with anilines as a TC and phenol as a model antioxidant, $\mathrm{pH}$ trends of the inhibitory effect could be rationalized based on the reduction potential difference $\left(\Delta E_{\text {red }}\right)$ of phenoxyl/phenol and anilinyl/aniline couples. Our results indicate that the lightinduced transformation of aromatic amines in the aquatic environment is governed by the pH-dependent inhibitory effects of antioxidant phenolic moieties of DOM and $\mathrm{pH}$-dependent processes related to the formation of amine oxidation intermediates.

KEYWORDS: excited triplet states, radicals, speciation, reduction potential, photolysis, humic substances, antibiotics

\section{INTRODUCTION}

Direct and indirect photochemical reactions are important transformation pathways of biomolecules and contaminants in the aquatic environment, ${ }^{1-3}$ leading, for example, to detoxification of halogenated disinfection byproducts. ${ }^{4,5}$ Dissolved organic matter (DOM) is a chemically complex and structurally diverse component of natural water bodies that plays critical roles in a wide range of environmentally relevant processes. $^{6-8}$ In clear surface waters, DOM is the main absorber of sunlight in the upper water layer. Photon absorption by DOM can trigger both indirect phototransformation of contaminants and photoinactivation of pathogens but also result in DOM photobleaching. ${ }^{9-18}$ Photochemical processes in surface waters involve various short-lived reactive species and different reaction pathways, ${ }^{19-23}$ with DOM and its excited triplet states $\left({ }^{3} \mathrm{DOM}^{*}\right)$ as key participants. ${ }^{24-29}$ In fact, DOM plays a dual role in photochemical transformation reactions by acting both as a photosensitizer, enhancing photochemical transformations, and as an antioxidant, slowing down photochemical transformations by quenching reactive intermediates.

Excited triplet states, including ${ }^{3} \mathrm{DOM}^{*}$, are generally known to undergo electron-transfer reactions. ${ }^{30}$ According to eq 1 ,
${ }^{3} \mathrm{DOM}^{*}$ may withdraw an electron from an oxidizable organic target compound (TC) to form a DOM radical anion $\mathrm{DOM}^{\bullet-}$ and a one-electron oxidized contaminant radical cation $\mathrm{TC}^{\bullet+}$. The latter are short-lived intermediates that may further react to stable oxidation products $\mathrm{TC}_{\mathrm{ox}}$ (eq 2). However, $\mathrm{TC}^{\bullet+}$ may itself abstract an electron from an electron-rich antioxidant (AO) moiety, a reaction that reconstitutes the parent TC (eq 3). Reaction with the antioxidant thus quenches TC oxidation.

$$
\begin{aligned}
& { }^{3} \mathrm{DOM}^{*}+\mathrm{TC} \rightarrow \mathrm{DOM}^{\bullet-}+\mathrm{TC}^{\bullet+} \\
& \mathrm{TC}^{\bullet+} \rightarrow \mathrm{TC}_{\mathrm{ox}} \\
& \mathrm{TC}^{\bullet+}+\mathrm{AO} \rightarrow \mathrm{TC}+\mathrm{AO}^{\bullet+}
\end{aligned}
$$

The inhibition of triplet-induced reactions through antioxidants lowers the rate of TC transformation. Phenolic moieties,

Received: May 21, 2021

Revised: August 20, 2021

Accepted: October 20, 2021

Published: October 29, 2021 
which are abundant in $\mathrm{DOM},{ }^{31,32}$ are considered a major reservoir of antioxidant capacity in natural waters.

The effect of DOM and model antioxidants on tripletinduced oxidations of organic compounds has been investigated in several recent studies. ${ }^{33-42}$ These studies showed that DOM inhibits the oxidative transformation of a wide range of environmentally relevant compounds, particularly when containing aniline functional groups, such as sulfonamide antibiotics, and phenolic groups. ${ }^{33}$ The inhibitory effect of terrestrial DOM was found to be substantially higher than that of aquatic DOM. ${ }^{34}$ The antioxidant properties of DOM were characterized using electrochemical techniques, which provided evidence for phenolic moieties within DOM as main antioxidants. ${ }^{43,44}$ The role of phenolic moieties as antioxidants in DOM was further characterized by kinetic irradiation experiments in model systems with triplet photosensitizers and either phenolic antioxidants or DOM as an antioxidant. ${ }^{35}$ Partial preoxidation of DOM by ozone diminished its antioxidant activity ${ }^{38}$ and also decreased the inhibitory effect of DOM on triplet-induced transformations. ${ }^{36}$ Quenching of triplet states by DOM was ruled out as a potential cause of the inhibitory effect. ${ }^{45}$ The inhibitory effect of DOM has been reported for radical cations induced by direct absorption of light. $^{39}$ However, reformation of initial compounds from metastable transformation products may also occur for other types of photochemical reaction pathways, such as reversible photohydrations and photooxygenations. ${ }^{46-49}$

The aims of this study were (1) to investigate how the inhibitory effect of DOM changes with $\mathrm{pH}$ and (2) to compare this effect to other $\mathrm{pH}$-dependent effects on triplet-induced transformation kinetics. We anticipated that varying the $\mathrm{pH}$ would largely alter the inhibitory effect due to causing speciation shifts of the phenolic antioxidant moieties within the DOM. These phenolic moieties deprotonate to phenolates over a wide $\mathrm{pH}$ range centered at $\approx 9.7 .^{32,50}$ Phenolates are more readily oxidized than undissociated phenols because their one-electron oxidation potential is $\approx 0.7 \mathrm{~V}$ higher compared to their protonated counterparts. ${ }^{51}$ Therefore, the working hypothesis for this study was that the inhibitory effect of DOM, as well as of phenolic model antioxidants, increases with $\mathrm{pH}$ from neutral to basic solution $\mathrm{pH}$ conditions.

However, this working hypothesis may be simplistic because more complex $\mathrm{pH}$ dependencies are conceivable. $\mathrm{pH}$ effects on radical intermediates might weaken or even reverse the trend expected based on our working hypothesis. $\mathrm{pH}$ affects not only the equilibrium speciation of aniline radical cations, ${ }^{52,53}$ which are key intermediates for the inhibitory effect (see eq 3 ), but also the rates of the corresponding deprotonation and protonation reactions. ${ }^{54}$ With increasing $\mathrm{pH}$, the deprotonation rates of the radical cation $\mathrm{TC}^{\bullet+}$ are expected to increase and the protonation equilibrium is shifted to the deprotonated species. The latter are weaker oxidants than the radical cations, and a decrease in the reduction rate of the radicals and thus a smaller inhibitory effect is expected. Furthermore, $\mathrm{TC}^{\bullet+}$ and their deprotonated counterparts are possibly involved in other $\mathrm{pH}$-dependent reactions leading to their further transformation to oxidized products or to reduction back to their parent compounds. Finally, $\mathrm{pH}$ may also alter transformation kinetics by changing light absorption characteristics of DOM, production rates and reactivities of ${ }^{3} \mathrm{DOM}^{*}$ (generated from a variety of different precursor chromophores), and changes in TC ground-state speciation. Despite the importance of $\mathrm{pH}$ on DOM photochemistry in aquatic photochemical reactions, most studies considering the effect of $\mathrm{pH}$ on surface water photochemistry focus on indirect photodegradation of specific target compounds while providing an explanatory framework around $\mathrm{pH}$-induced shifts of reactive species steady-state concentration and target compound speciation ${ }^{55-57}$ but without considering photochemical or photophysical processes, such as changes in fluorescence intensity with $\mathrm{pH}^{58}$ within DOM in detail. $\mathrm{pH}$ is an important driver in DOM photobleaching, which increases toward both lower and higher $\mathrm{pH}$ exhibiting a minimum around $\mathrm{pH}$ 6-6.5..$^{59}$ Increased photobleaching at higher $\mathrm{pH}$ has been explained with the expansion of DOM and its chromophores, ${ }^{60}$ along with increasing light absorption with increasing $\mathrm{pH}^{61}$ and enhanced internal charge transfer due to deprotonated phenolic moieties. $^{62}$

The irradiation experiments for this study were carried out with photosensitizers, antioxidants, and TCs chosen based on previous studies ${ }^{34-36,51,63,64}$ in solutions covering a range of $\mathrm{pH} 6-11$. This $\mathrm{pH}$ range was selected to include the $\mathrm{pH}$ of most natural surface waters $(\sim 7-9)$ and to cover protonation equilibria of phenolic moieties of DOM. Lower $\mathrm{pH}$ within the range of $\mathrm{pH} \sim 2-6$, which are, for example, occurring in atmospheric water $^{65}$ and acid mine drainage, ${ }^{66}$ were not included due to the additional complexity arising by protonation equilibria of TCs and carboxylic moieties within DOM $\left.\left(\mathrm{p} K_{\mathrm{a}} \approx 4\right)\right)^{32,50}$ In the studied $\mathrm{pH}$ range, carboxylic moieties of DOM are not expected to play an important role for the investigated kinetic changes because they are mostly deprotonated.

Aromatic ketones and DOM isolates were employed as photosensitizers. Suwannee River fulvic acid (SRFA) and Nordic aquatic fulvic acid (NAFA) served as representative DOMs or terrestrial origin, derived from higher plants, while Pony Lake fulvic acid (PLFA) served as representative aquatic DOM derived mostly from microbial sources. ${ }^{67}$ Anilines, including sulfonamides, and 4-cyanophenol served as TCs. Choice of TCs was based on previous studies characterizing the inhibitory effect of DOM on anilines and sulfonamides at fixed $\mathrm{pH}^{33-35}$ the importance of anilines and their derivatives as aquatic contaminants, ${ }^{68,69}$ including their frequent use as model pollutants, ${ }^{70}$ and the availability of radical cation standard one-electron reduction potential data. Sulfonamides are a broad class of high-usage classic antibiotics with various ecotoxicological effects in the environment that can be frequently detected in surface waters, including at above micromolar concentrations. ${ }^{71}$ 4-Cyanophenol was chosen as a representative phenolic compound without antioxidant properties. Both unsubstituted phenol and DOM isolates were used as antioxidants. Four different types of experimental systems were utilized to study TC phototransformation, namely: System 1, employing either a model photosensitizer or DOM (in the latter case, DOM acted both as a photosensitizer and an antioxidant); System 2, employing a model photosensitizer and DOM as an antioxidant; System 3, employing DOM as a photosensitizer and a model antioxidant; and System 4, employing a model photosensitizer and a model antioxidant.

\section{MATERIALS AND METHODS}

Chemicals. A list of target compounds, photosensitizers, antioxidants, and DOMs used in this study is provided in Table 1. Supplier and purity details, including information on additional chemicals used and preparation of stock solutions, are provided in the Supporting Information (SI), Text S1. 
Table 1. Target Compounds, Model Photosensitizers, Model Antioxidant, and DOM Isolates, with Acid Dissociation Constants $\left(\mathrm{p} K_{\mathrm{a}}\right)$ and One-Electron Standard Reduction Potentials $\left(E_{\mathrm{red}}^{\circ}\right)$ of Their Relevant Reactive Species

\begin{tabular}{|c|c|c|c|c|c|c|}
\hline & compound & abbreviation & CAS-RN IHSS no. & $\mathrm{p} K_{\mathrm{a}}^{a}$ & $\mathrm{p} K_{\mathrm{a}}^{* b}$ & $E_{\text {red }}^{\circ}{ }^{c}(\mathrm{~V}$ vs SHE $)$ \\
\hline \multirow[t]{2}{*}{ model photosensitizers } & 2-acetonaphthone & $2 \mathrm{AN}$ & $93-08-3$ & & $1.7^{72}$ & $1.10,^{45,73} 1.34^{74}$ \\
\hline & 4-carboxbenzophenone & CBBP & $611-95-0$ & $4.57^{75}$ & n.a. ${ }^{76 d}$ & $1.83^{45,77}$ \\
\hline \multirow[t]{8}{*}{ target compounds } & aniline & ANI & $62-53-3$ & $4.87^{75}$ & $7.05^{52}$ & $1.02^{53}$ \\
\hline & 4-methoxyaniline & $4 \mathrm{MtA}$ & $104-94-9$ & $5.36^{75}$ & $9.6^{53}$ & $0.79^{53}$ \\
\hline & 4-methylaniline & 4MA & $106-49-0$ & $5.08^{75}$ & $8.5^{53}$ & $0.92^{53}$ \\
\hline & $N, N$-dimethylaniline & DMA & $121-96-7$ & $5.07^{75}$ & n.a. & $0.87^{78}$ \\
\hline & sulfamethoxazole & SMX & $723-46-6$ & $1.6 \pm 0.2,5.7 \pm 0.2^{79}$ & n.a. & n.a. \\
\hline & sulfachloropyridazine & SCPD & $80-32-0$ & $2 \pm 3,5.9 \pm 0.3^{79}$ & n.a. & n.a. \\
\hline & sulfadiazine & $\mathrm{SD}$ & $38-35-9$ & $2 \pm 1,6.4 \pm 0.6^{28}$ & $2.9^{80}$ & $1.30^{c}, 1.09^{80 e}$ \\
\hline & 4-cyanophenol & $4 \mathrm{CNP}$ & $767-00-0$ & $7.97^{75}$ & $<0^{81}$ & $1.71^{51 c}, 1.12^{82 f}$ \\
\hline model antioxidant & phenol & & $108-95-2$ & $9.99^{75}$ & $-2^{81,83}$ & $1.5^{51 c}, 0.79^{82 f}$ \\
\hline \multirow[t]{3}{*}{ DOM isolates } & Suwannee River fulvic acid & SRFA & $2 \mathrm{~S} 101 \mathrm{~F}$ & $3.76,9.84^{50}$ & n.a. & n.a. \\
\hline & Pony Lake fulvic acid & PLFA & 1R109F & $4.52,9.48^{84}$ & n.a. & n.a. \\
\hline & Nordic aquatic fulvic acid & NAFA & 1R105F & $3.79,9.67^{32}$ & n.a. & n.a. \\
\hline
\end{tabular}

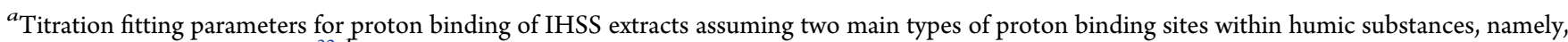
carboxylic acids and phenols. ${ }^{32}{ }^{b}$ Dissociation constant of relevant reactive species: protonated excited triplet state (photosensitizer), radical cation (target compound), or protonated phenoxy radical (target compound or model antioxidant). ${ }^{c}$ Standard one-electron reduction potential of the excited triplet state (photosensitizer) or radical cation $\left(\mathrm{TC}^{\bullet+} / \mathrm{TC}\right)$, except where noted (unit: $\mathrm{V}$ vs standard hydrogen electrode, SHE). ${ }^{d}$.a.: not available. ${ }^{e}$ Standard one-electron reduction potential of sulfadiazine radical/sulfadiazine anion $\left(\mathrm{SD}^{\bullet} / \mathrm{SD}^{-}\right) .{ }^{f_{\text {Standard }}}$ one-electron reduction potential of phenoxyl radical/phenolate $\left(\mathrm{PhO}^{\bullet} / \mathrm{PhO}^{-}\right)$.

Preparation of Solutions. All aqueous solutions were prepared using ultrapure water (Milli-Q, Millipore). Solutions for irradiations were prepared in $20 \mathrm{~mL}$ (final volume) capped quartz-glass tubes with a headspace of approximately $2 \mathrm{~mL}$ and contained $5 \mathrm{mM}$ phosphate buffer, which was used throughout the investigated $\mathrm{pH}$ range of 6-11. Phosphate-buffered solutions for all experiments were used to avoid possible effects on TC transformation kinetics due to the increasing importance of carbonate radicals in carbonate-buffered systems at elevated $\mathrm{pH} .{ }^{26,55,56}$ Note that experiments conducted at $\mathrm{pH}$ 9 and 10 were not in the optimum buffer range of phosphate. However, $\mathrm{pH}$ measurements before and after each set of irradiations showed that the $\mathrm{pH}$ values drifted by $\leq 0.05 \mathrm{pH}$ units, even under these alkaline conditions. Solutions contained different combinations of a single TC, a model photosensitizer or DOM as a photosensitizer, and a model antioxidant or DOM as an antioxidant. The initial TC concentration was $5 \mu \mathrm{M}$. Concentrations of model photosensitizers were $50 \mu \mathrm{M}$ for CBBP and $10-100 \mu \mathrm{M}$ for $2 \mathrm{AN}$ (Table S5a,b for different TCs). TC, model photosensitizer, and phenol addition to the solutions did not change its $\mathrm{pH}$. The DOM concentration was $2.5 \mathrm{mg} \mathrm{C} \mathrm{L}^{-1}$ (applied in most cases) or $1.0 \mathrm{mg} \mathrm{C} \mathrm{L}^{-1}$. Addition of DOM stock solutions decreased the solution $\mathrm{pH}$ by $0.1 \pm 0.02$ units at $\mathrm{pH} 9-11$. Possible changes in TC phototransformation kinetics resulting from this slight $\mathrm{pH}$ decrease were assumed to be within the experimental error. Thus, we report target integer $\mathrm{pH}$ values in the Results and Discussion section. The concentrations of the model antioxidant phenol were 10 or $25 \mu \mathrm{M}$. The added phenol concentration is reasonably comparable to the concentration of both phenolic moieties and electron-donating groups within solutions containing $1-2.5 \mathrm{mg} \mathrm{C} \mathrm{L}^{-1} \mathrm{DOM}^{35}$ SRFA and NAFA phenolic content has been measured via titration and $1 \mathrm{mg} \mathrm{C} \mathrm{L} \mathrm{L}^{-1}$ corresponds to $3 \mu \mathrm{M}$ phenolic moieties, while not all phenolic moieties act as antioxidants. ${ }^{32}$ Similarly, the electron-donating capacity (EDC) for a variety of humic substances was measured at an applied potential of $E_{\mathrm{h}}=$
$0.61 \mathrm{~V}, \mathrm{pH} 7$, and ranged approximately from 0.6 to $1.8 \mu \mathrm{M}$ EDC per mg humic substance. ${ }^{43}$

Irradiation Experiments. The irradiation setup consisted of a merry-go-round photoreactor (Hans Mangels, Germany) that was equipped with a $500 \mathrm{~W}$ medium-pressure lamp, a borosilicate glass cooling jacket, a $0.15 \mathrm{M}$ sodium nitrate filter solution which cut off lamp emission wavelengths $\leq 320 \mathrm{~nm}$, to minimize direct phototransformation of TCs, and a cooling system adjusted to $25{ }^{\circ} \mathrm{C}\left( \pm 0.2{ }^{\circ} \mathrm{C}\right)$. Further details on the setup are provided elsewhere. ${ }^{34}$ Model and DOM photosensitizer concentrations and irradiation times for complete kinetics experiments (SI Tables S2, S3, and S5-S8) were optimized according to preliminary trials and results of previous studies, ${ }^{34-36}$ irradiation times ranged from 5 to 90 min. Differences in model photosensitizer concentration across different experiments and $\mathrm{pH}$ are not expected to affect normalized reaction rate constants. To determine transformation kinetics of the TCs, six samples of $400 \mu \mathrm{L}$ were withdrawn from each quartz tube in equidistant time intervals during photoirradiation. Samples were immediately stored at 4 ${ }^{\circ} \mathrm{C}$ and analyzed by high-performance liquid chromatography (HPLC) within $36 \mathrm{~h}$. Most experiments were performed in duplicate (a few in triplicate) and were found to yield reproducible results with a deviation in reaction rate constants of $<10 \%$ between repetition experiments, except for a few experiments conducted at $\mathrm{pH} 10$ and 11 with higher deviations. Details on analytical methods, including HPLC analysis, UV-vis absorption, and $\mathrm{pH}$-measurements are provided in Text S2 and Table S1.

Data Analysis. The depletion of TCs was fitted assuming pseudo-first-order reaction kinetics (i.e., reaction rate constants $k\left(\mathrm{~s}^{-1}\right)$ equalled the linear slopes of TC concentrations, expressed in natural logarithmic units, vs irradiation times). To achieve comparable results across all $\mathrm{TC} /$ photosensitizer/ inhibitor $/ \mathrm{pH}$ combinations, reaction rate constants were first corrected for direct phototransformation of the TC (see Text $\mathrm{S} 3$ for discussion on the effect of $\mathrm{pH}$ on direct phototransformation for single TCs and Tables S2 and S3 for 

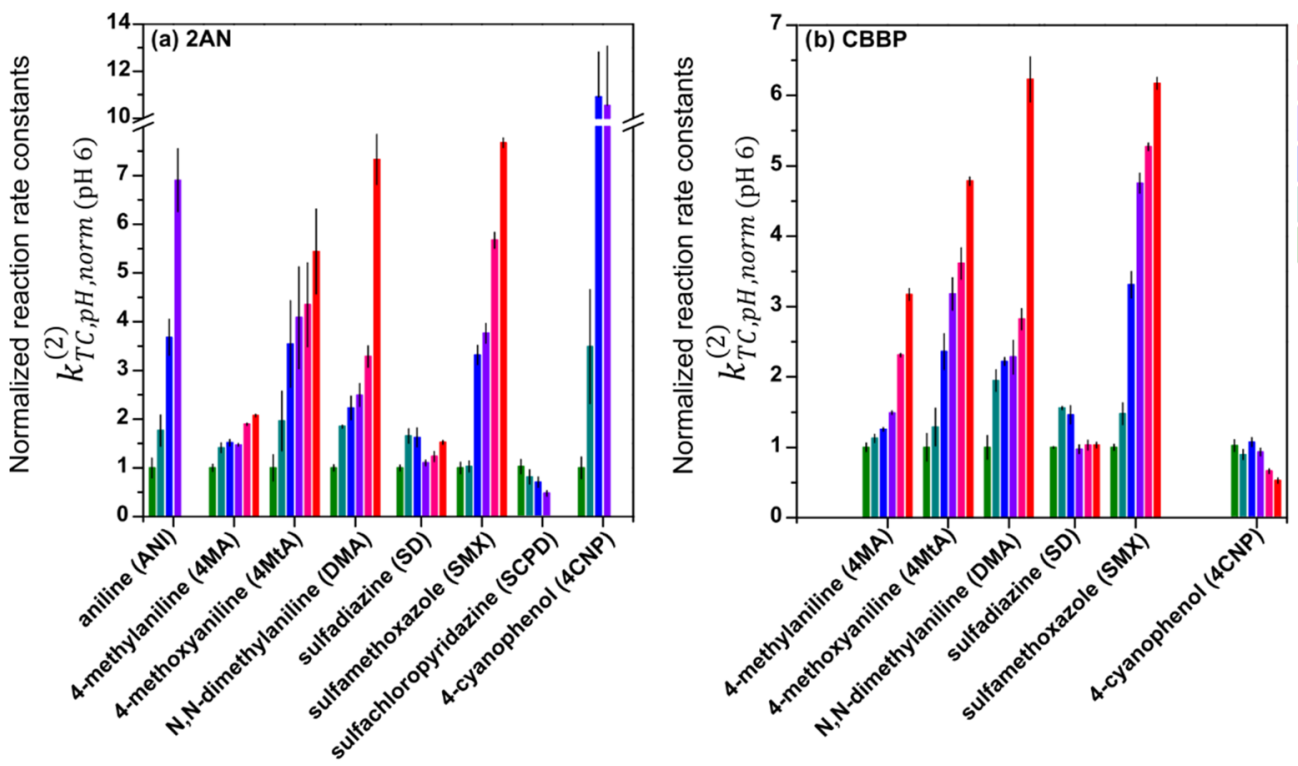

$\mathrm{pH} 11$

$\mathrm{pH} 10$

$\mathrm{pH} 9$

$\mathrm{pH} 8$

$\mathrm{pH} 7$

$\mathrm{pH} 6$
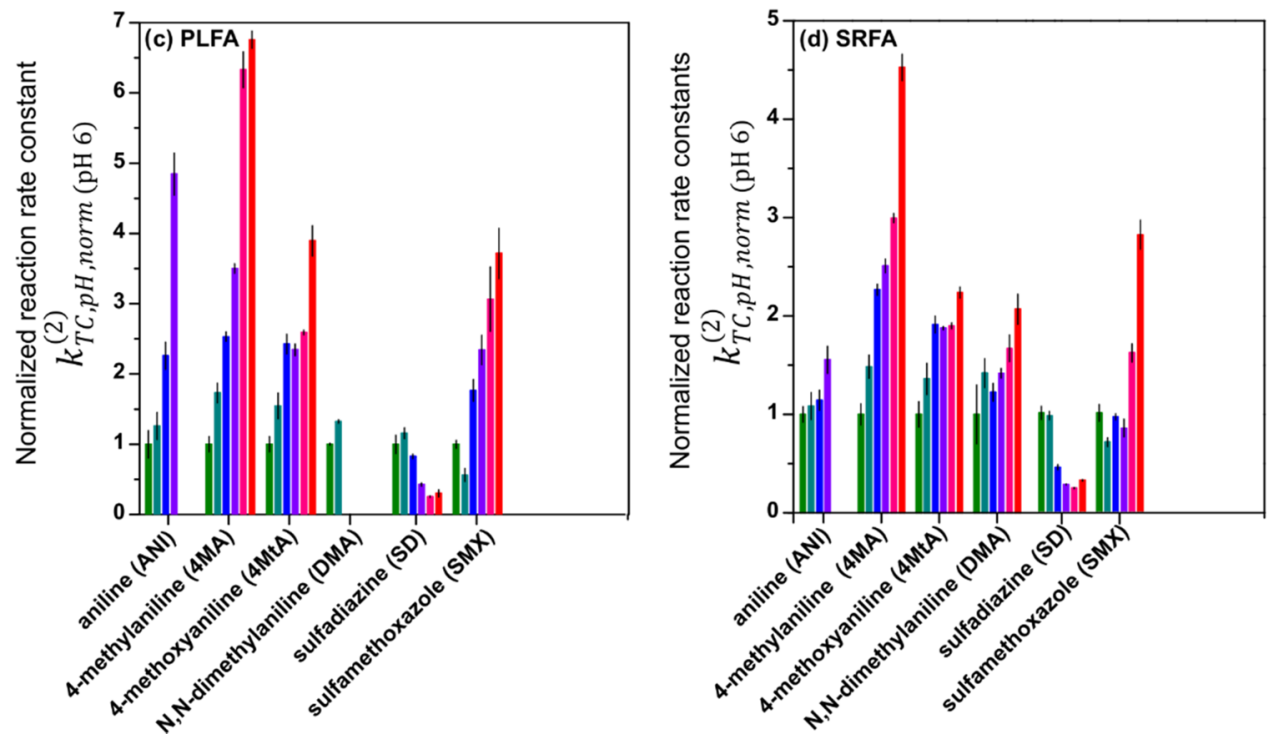

Figure 1. Pseudo-first-order rate constants, normalized to the corresponding values at $\mathrm{pH} 6$, for the transformation of target compounds photosensitized by model photosensitizers (a) 2-acetonaphthone (2AN), (b) benzophenone-4-carboxylate (CBBP), or dissolved organic matter isolates, (c) Pony Lake fulvic acid (PLFA), and (d) Suwannee River fulvic acid (SRFA) at several different pH values indicated in the legend. Error bars show $95 \%$ confidence intervals (Tables S4-S8).

measured direct phototransformation rate constants) and for System 2 experiments (i.e., for solutions with model photosensitizers and DOM as an antioxidant), to compensate for the photosensitizing effect of DOM. These corrections were performed separately for separate $\mathrm{pH}$ values by subtracting reaction rate constants for each $\mathrm{TC}$ in pure water or in solutions containing only DOM without model sensitizers from rate constants obtained with model sensitizers (either in the absence or presence of DOM). Light-screening correction was applied in a second step using the factors for different photosensitizer and inhibitor combinations listed in Tables S9-S14. Details on the determination of correction factors are provided elsewhere. ${ }^{36}$ Consistent with previous publications, the corrected rate constants are labelled with the superscript (2) (i.e., $k^{(2)}$ ) to indicate that two corrections were made. ${ }^{34-36}$ In no case did the corrections alter trends that were apparent already in the uncorrected data. UV-absorption spectra of TCs and phenol are shown in Figures S1 and S2. UV-vis absorption spectra of model and DOM photosensitizers, molar (model photosensitizers), and specific absorption coefficients (DOM) at the relevant wavelengths of the irradiation system are provided in Figure S4 and Table S4, alongside a discussion on the effect of spectral changes of both model photosensitizers and DOM on the observed rate constants in this study, as well as the importance of $\mathrm{pH}$ induced changes in photophysical processes (Text S4).

\section{RESULTS AND DISCUSSION}

Transformation of TCs by Model Photosensitizers and DOM (System 1). We determined the rate constants of indirect phototransformation for nine TCs in combination with two model photosensitizers, 2AN (Figure 1a) and CBBP (Figure 1b), and two DOM isolates, PLFA (Figure 1c) and SRFA (Figure 1d) over the $\mathrm{pH}$ range of 6-11. To facilitate comparison between different TCs and photosensitizers, the displayed rate constants, $k_{\mathrm{TC}, \mathrm{pH}, \text { norm}}^{(2)}$ were corrected rate 
constants $\left(k_{\mathrm{TC} \mathrm{pH}}^{(2)}\right)$ normalized to the value obtained at the lowest tested $\mathrm{pH}$ of $6\left(k_{\mathrm{TC}, \mathrm{pH}}^{(2)}\right)$, i.e., $k_{\mathrm{TC}, \mathrm{pH}, \text { norm }}^{(2)}=k_{\mathrm{TC}, \mathrm{pH}}^{(2)} /$ $k_{\mathrm{TC}, \mathrm{pH}}^{(2)}$. Numerical values of all of these rate constants are provided in Tables S2, S3, and S5-S8, in the SI.

The rate constants in systems containing a model sensitizer (either 2AN or CBBP) reflect only the effect of $\mathrm{pH}$ on photosensitized TC transformation as there were no antioxidants in these solutions, and thus no inhibitory effects. Rate constants of TC phototransformation in the presence of PLFA and SRFA reflect the combined effect of DOM photosensitization and inhibitory effects through DOM antioxidant moieties. Concerning the effect of reactive oxygen species with changing $\mathrm{pH}$, Text S5 discusses the role of superoxide and in detail the possible impact of singlet oxygen $\left({ }^{1} \mathrm{O}_{2}\right)$ on the observed rate constants. In summary, the impact of ${ }^{1} \mathrm{O}_{2}$ is expected minor based on its available reaction rate constants with TCs.

In the systems containing the model photosensitizers $2 \mathrm{AN}$ or CBBP, the transformation rate constants of anilines (ANI, 4MA, 4MtA, and DMA) strongly increased with increasing $\mathrm{pH}$, between a factor of 2.1 (4MA) and 9.3 (DMA), relative to the lowest rate constant measured at $\mathrm{pH}$ 6. This $\mathrm{pH}$ trend for anilines may be rationalized by aniline radical cations formed through one-electron oxidation deprotonating at higher $\mathrm{pH}$. For ANI, 4MA, and 4MtA, the resulting anilinyl radicals are expected to be more prone to coupling reactions, which would compete with a possible reduction by superoxide (Text S5). For DMA, deprotonation of the radical cation would lead to a carbon-centered radical on one of the methyl groups and further degradation, also competing with a possible reduction by superoxide (Text S5). As compared to the anilines, there was no consistent $\mathrm{pH}$ trend for the sulfonamides SMX, SCPD, and $\mathrm{SD}$. With increasing $\mathrm{pH}$, the phototransformation rate constants strongly increased for SMX, moderately decreased for SPCD, while no clear $\mathrm{pH}$ trend was observed for SD.

When comparing transformation by the two photosensitizers $2 \mathrm{AN}$ and $\mathrm{CBBP}$, the effect of $\mathrm{pH}$ on the normalized pseudofirst-order rate constants for each individual TC was similar with a single exception: For $4 \mathrm{CNP}\left(\mathrm{p} K_{\mathrm{a}}\right.$ : 7.97$)$, the normalized rate constants strongly increased with $\mathrm{pH}$ for $2 \mathrm{AN}$ but not for CBBP. This observation can be explained by the different oneelectron reduction potentials of the photosensitizers in their excited triplet states $\left(E_{\mathrm{red}}^{0 *}\left({ }^{3}\right.\right.$ Sens $* /$ Sens $\left.\left.^{\bullet-}\right)\right)$. Assuming that the phototransformation of $4 \mathrm{CNP}$ is initiated by a one-electron transfer to the excited triplet state of the photosensitizer, ${ }^{51}$ excited triplet $\mathrm{CBBP}\left(E_{\mathrm{red}}^{0 *}\left({ }^{3} \mathrm{CBBP} * / \mathrm{CBBP}^{\circ-}\right)=1.83 \mathrm{~V}\right.$ vs standard hydrogen electrode ( $\mathrm{SHE})$ ) is expected to undergo a diffusion-controlled reaction with both the undissociated and deprotonated forms of 4CNP (having one-electron oxidation potentials of -1.71 and $-1.12 \mathrm{~V}$ vs SHE, respectively), which explains the lack of $\mathrm{pH}$ effect on the transformation rate of $4 \mathrm{CNP}$. In contrast, for ${ }^{3} 2 \mathrm{AN}^{*}$ with a lower one-electron reduction potential $\left(E_{\mathrm{red}}^{0 *}\left({ }^{3} 2 \mathrm{AN}^{*} / 2 \mathrm{AN}^{\bullet-}\right)=1.10-1.34 \mathrm{~V}\right.$ vs $\mathrm{SHE})$, a fast reaction is only expected to occur with the deprotonated form of 4CNP, explaining the enhancement in the transformation rate of $4 \mathrm{CNP}$ with increasing $\mathrm{pH}$.

In qualitative terms, TC reaction rate constants with DOM as a photosensitizer (Figure $1 \mathrm{c}, \mathrm{d}$ ) had a similar $\mathrm{pH}$ dependence as those observed with the model photosensitizers. This finding supports that both $2 \mathrm{AN}$ and CBBP are suitable model photosensitizers to mimic the ${ }^{3} \mathrm{DOM}^{*}$-induced TC oxidation over the studied $\mathrm{pH}$ range. However, compared to the experimental series with model photosensitizers only, we expected decreased photosensitized transformation rate constants with increasing $\mathrm{pH}$ due to the presence of DOM antioxidant moieties that inhibit transformation. Given the two competing processes of photosensitization and inhibition in systems containing DOM, the similar $\mathrm{pH}$ trends observed in the presence and absence of DOM antioxidant moieties suggest that inhibition by DOM generally played a minor role. The only exception to this conclusion is the reaction of SD: its rate constants were not strongly affected by $\mathrm{pH}$ for model sensitizers but decreased with increasing $\mathrm{pH}$ when DOM was the photosensitizer. The latter finding concurs with the expectation that the inhibition caused by antioxidant moieties of DOM increases with increasing $\mathrm{pH}$. The absence of a significant $\mathrm{pH}$ effect for SD transformation without antioxidants agrees with previous observations. ${ }^{28}$ This difference to the behavior of the anilines and SMX is possibly related to the particular pathway of triplet-sensitized phototransformation of sulfonamides exhibiting a six-membered heterocyclic substituent (such as SD, but not SMX), which leads to the formation of $\mathrm{SO}_{2}$ extrusion products. ${ }^{28}$ The limited amount of data available for SCPD appear to indicate a $\mathrm{pH}$ dependence of the rate constants more similar to SD than SMX, which concurs with the same type of substituent carried by SD and SCPD.

Note, for DOM as a photosensitizer, electrostatic attraction between negatively charged DOM and TC compounds can be neglected over the whole $\mathrm{pH}$ range, since none of the TCs is present as a positively charged (cationic) species at $\mathrm{pH} \geq 6$. This includes $\mathrm{SD}$, exhibiting a significant speciation change between $\mathrm{pH} 6$ and 7 from neutral (zwitterionic) to anionic, while changes on the photosensitized rate constant of SD are small in this $\mathrm{pH}$ span compared to those observed for $\mathrm{pH} 7-$ 11.

Assessing the Individual Inhibition and Photosensitization Contribution in DOM-Induced Phototransformations. Due to the intrinsic coexistence of photosensitizing and antioxidant moieties in DOM, the individual contribution of the two types of moieties can be determined using comparative irradiation experiments. In previous studies, we expressed inhibition by DOM based on a calculated inhibition factor (IF). ${ }^{34-36}$ IF was defined as the ratio of rate constants for the transformation of a TC in the presence and absence of antioxidants obtained with the same photosensitizer (under identical irradiation conditions). Here, we use an analogous concept: the normalized reaction rate constants for the transformation of a TC photosensitized by a given DOM at a certain $\mathrm{pH}$ are divided by the corresponding normalized rate constants obtained using a given model photosensitizer (in the absence of inhibitors). This ratio is termed here as "comparative inhibition factor" (CIF), expressed as: CIF =

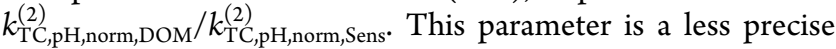
indicator of the inhibitory effect than IF because it is based on rate constants obtained using two different photosensitizers (i.e., a given DOM and a given model sensitizer). In addition, DOM photosensitizer moieties are subject to changes in absorbance and possibly in intersystem crossing quantum yields with varying solution $\mathrm{pH}$ (Texts S4 and S5), while we do not expect such $\mathrm{pH}$ effects to occur for the used model photosensitizers.

Figure $2 \mathrm{a}-\mathrm{e}$ shows calculated CIF of the four DOM-model sensitizer combinations and six TCs. Note that the values of $\mathrm{CIF}$ at $\mathrm{pH} 6$ are always 1 (by definition). Therefore, CIF is not able to reveal an inhibitory effect at $\mathrm{pH} 6$ but is useful to describe the changes in inhibitory effect with increasing $\mathrm{pH}$. 

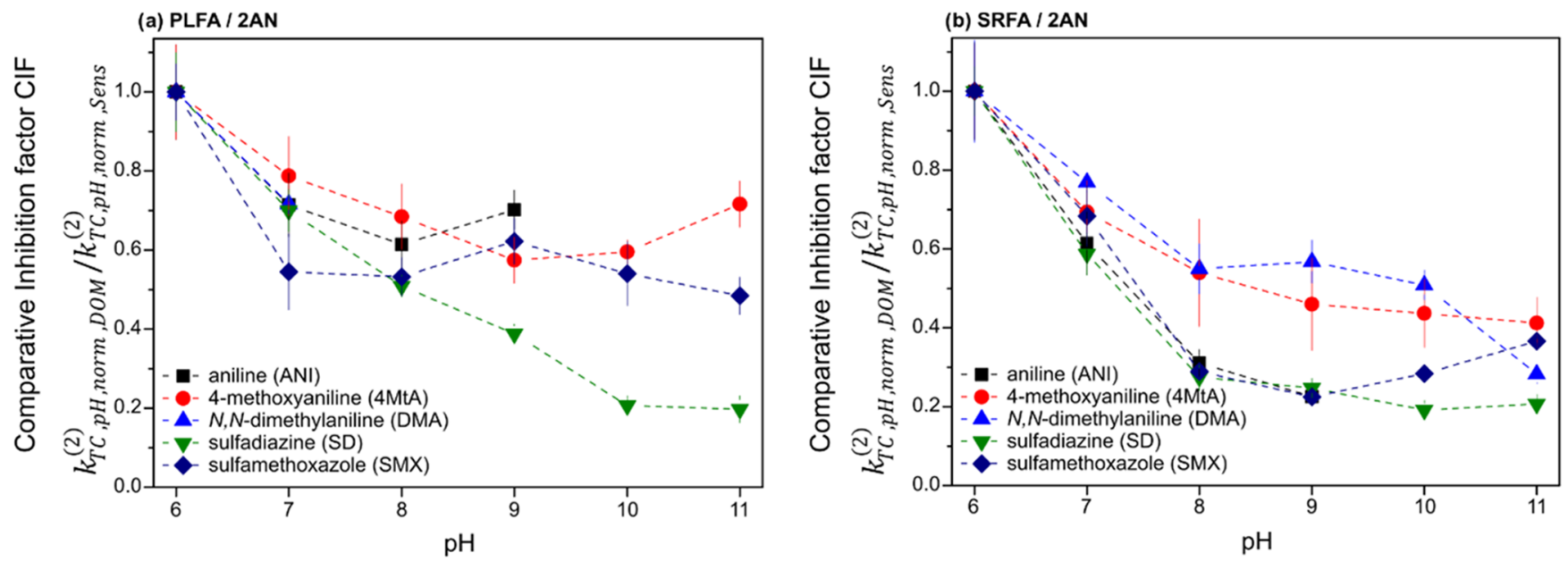

(c) PLFA / CBBP
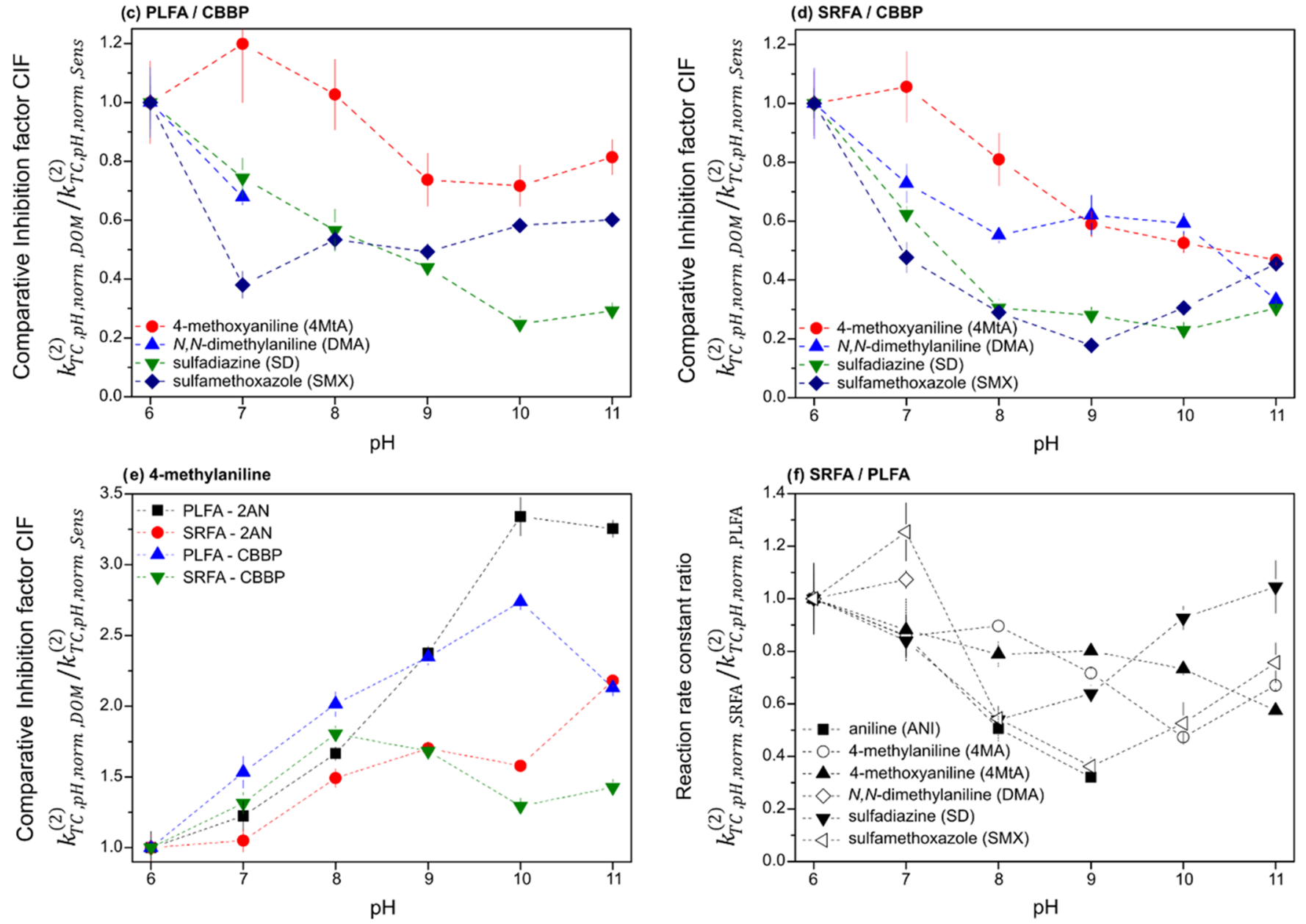

Figure 2. Comparative inhibition factors of photosensitized transformation of target compounds (TCs) for the DOM isolates $\left(2.5 \mathrm{mg} C \mathrm{~L}^{-1}\right)$ Pony lake fulvic acid (PLFA) and Suwannee River fulvic acid (SRFA) in relation to the model sensitizers 2-acetonaphthone (2AN) and benzophenone-4carboxylate (CBBP) (a-e) and a reaction rate constant ratio of SRFA and PLFA photosensitized transformations of TCs (f) at different $\mathrm{pH}$. Experimental error bars were determined by the error propagation law using $95 \%$ confidence intervals of pseudo-first-order transformation rate constants of single photosensitizer/TC systems.

We used the lowest tested $\mathrm{pH}$ value as the reference point for data evaluation primarily based on our initial hypothesis that phenolic antioxidant activity increases with increasing $\mathrm{pH}$. For most target compounds, CIF decreased as the $\mathrm{pH}$ increased (Figure $2 \mathrm{a}-\mathrm{d}$ ), supporting the hypothesis that the inhibitory effect of DOM increases with increasing $\mathrm{pH}$ because of an increased fraction of deprotonated phenolic moieties in the DOM. We observed the opposite trend for 4MA for which we currently have no explanation (Figure 2e): CIF increased with increasing $\mathrm{pH}$.

When evaluating data sets across different TCs, the decrease in CIF was largest over the circumneutral $\mathrm{pH}$ range between $\mathrm{pH} 6$ and 8. At mildly alkaline conditions from $\mathrm{pH} \mathrm{8,} \mathrm{the}$ increase in inhibition subsided or reversed. Also considering the observed exception for 4MA, these $\mathrm{pH}$ trends indicate that $\mathrm{CIF}$ changes with $\mathrm{pH}$ might depend on various factors, such as 

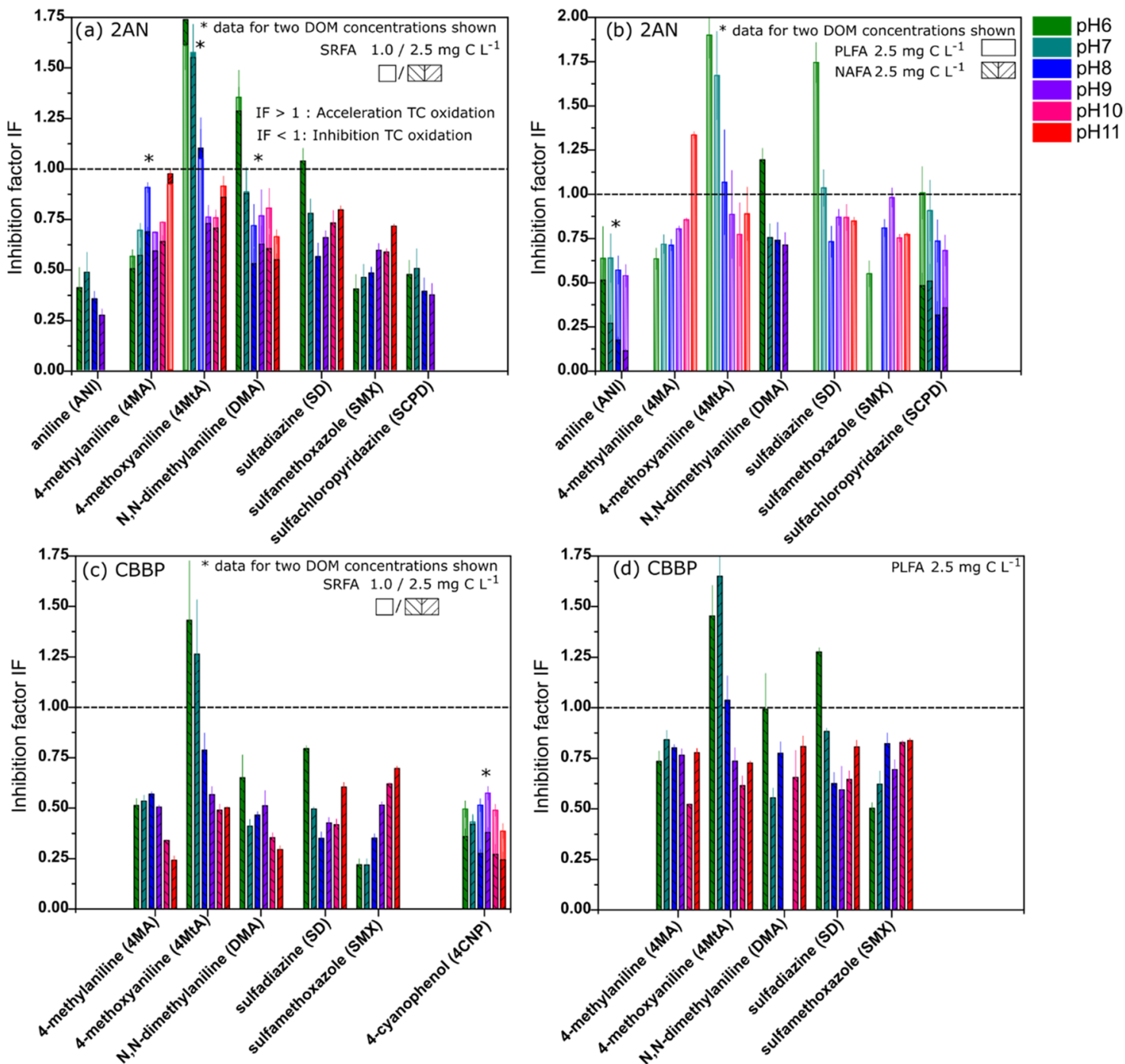

Figure 3. Inhibition factors (IF) for the transformation of target compounds (TCs; $x$-axis) photosensitized by 2-acetonaphthone (2AN) (a, b) and benzophenone-4-carboxylate (CBBP) (b-d) with the DOM isolates SRFA, PLFA, and NAFA in their role as natural antioxidants.

protonation equilibria involving $\mathrm{TC}^{\bullet+}$, the reactions of transformation intermediates of the TCs with superoxide radical anion to form transformation products or leading to reformation of the parent compound, or with DOM, yielding addition of the oxidized TCs to DOM. The latter reaction, which was suggested to occur for aniline in an oxidative aqueous environment, ${ }^{85}$ possibly affects in particular the transformation of 4MA, whose CIF exhibits a very distinct $\mathrm{pH}$ dependence.

Comparing Figure 2a,c and b,d suggests that CIF tends to be lower for SRFA compared to PLFA. A direct comparison is provided in Figure $2 \mathrm{f}$ based on the normalized reaction rate constants $k_{\mathrm{TC}, \mathrm{pH}, \mathrm{norm}, \mathrm{SRFA}}^{(2)} / k_{\mathrm{TC}, \mathrm{pH} \text {,norm,PLFA }}^{(2)}$ For most TCs, this ratio is smaller than unity for any $\mathrm{pH}$ value $\geq 7$, the lowest values being observed at $8 \leq \mathrm{pH} \leq 10$. This can be interpreted as an enhanced inhibitory effect of SRFA in the latter $\mathrm{pH}$ range compared to PLFA. In general, a higher inhibitory effect of SRFA compared to PLFA is expected based on previous studies and the higher concentration of antioxidant moieties in SRFA. ${ }^{34-36}$ The fact that the minimum values in CIF ratios are found in this $\mathrm{pH}$ range, but not exactly at the same $\mathrm{pH}$ value for any TC, suggests that the inhibitory effect is related to the protonation equilibria of phenolic moieties in DOM and the radical intermediates of each $\mathrm{TC}\left(\right.$ i.e., $\mathrm{TC}^{\bullet+}$ ). These aspects will be discussed in more detail when addressing results from System 4 experiments (vide infra).

A possible explanation for the different behavior of $4 \mathrm{MtA}$ in systems with $\mathrm{CBBP}$ and $2 \mathrm{AN}$ at $\mathrm{pH}$ below $\sim 7-8$ could be that due to the high reduction potential of excited triplet CBBP, secondary DOM-derived photo-oxidants are formed, which can transform the readily oxidizable $4 \mathrm{MtA}$ and would mask DOM-induced inhibition observed in the systems with $2 \mathrm{AN}$.

Transformation of TCs by Model Photosensitizers in the Presence of DOM as an Antioxidant (System 2). Figure 3 shows results for irradiations with model photosensitizers and DOM to assess the role of DOM as an antioxidant. Data are presented as inhibition factor (IF), which is the ratio of pseudo-first-order reaction rate constants with and without added DOM as an antioxidant (i.e., IF = $\left.k_{\mathrm{TC}, \mathrm{pH}, \mathrm{Sens}, \mathrm{AO}}^{(2)} / k_{\mathrm{TC}, \mathrm{pH}, \mathrm{Sens}}^{(2)}\right)$. The corrected reaction rate constants used in the calculation of IF are provided in Figures S8-S16. For most of the studied systems across all TCs and $\mathrm{pH}$ values, there was a significant inhibitory effect (IF $<1)$. The determined IF values are like those reported previously at $\mathrm{pH} 8$ for the same model photosensitizer, TC and DOM combinations. $^{33,34}$ The inhibitory effect at $2.5 \mathrm{mg} \mathrm{C} \mathrm{L}^{-1} \mathrm{DOM}$ 

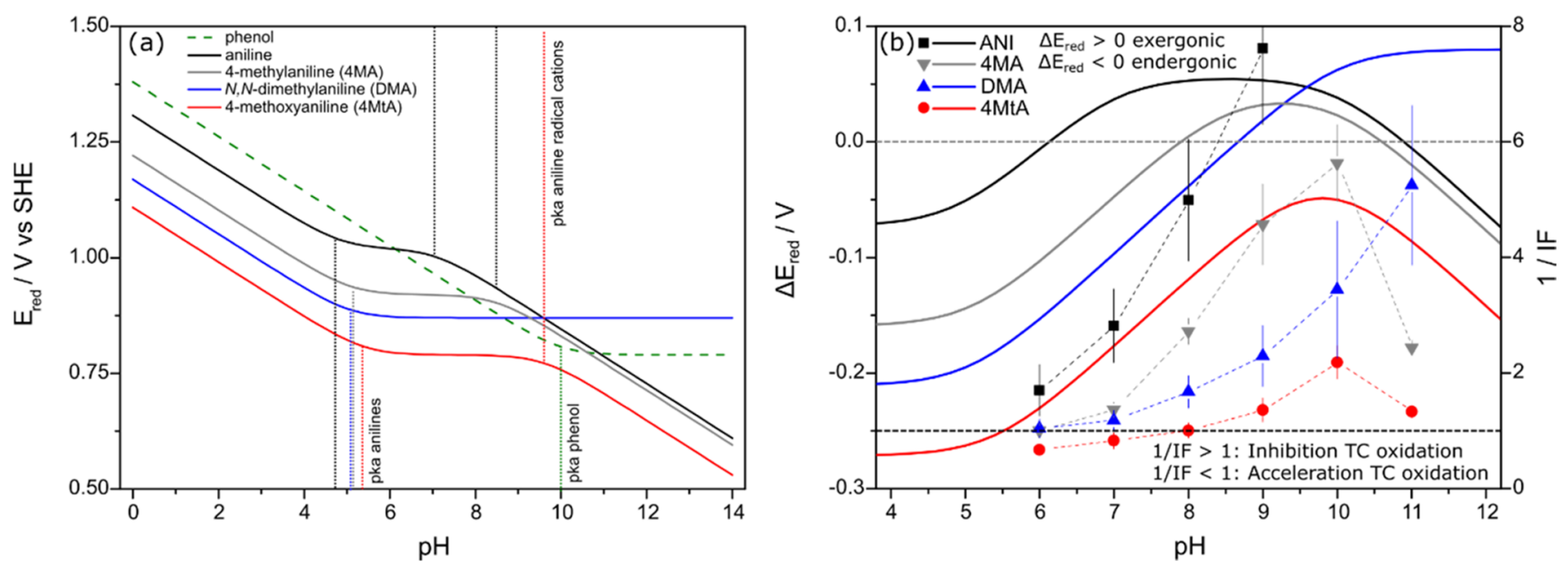

Figure 4. (a) One-electron reduction potentials $E_{\text {red }}$ (V vs standard hydrogen electrode (SHE)) for phenoxyl and anilinyl radicals as a function of $\mathrm{pH}$. Acid dissociation constants of the relevant species (see Table 1) are indicated by vertical dotted lines. (b) Difference in reduction potential $\Delta E_{\text {red }}$ of each anilinyl radical and phenoxyl radical for the $\mathrm{pH}$ range of 4-12 and inverse inhibition factors (1/IF) for anilines with $2 \mathrm{AN}$ as a model photosensitizer and phenol $(10 \mu \mathrm{M})$ as a model antioxidant. Calculations for $E_{\text {red }}$ and $\Delta E_{\text {red }}$ are available as Supporting Information .xlsx data file, with further consideration on the dependence of redox potentials of phenol and anilines, including redox equations provided in the SI, Text S6.

addition was stronger than at $1.0 \mathrm{mg} \mathrm{C} \mathrm{L}^{-1}$ across the whole $\mathrm{pH}$ range. Higher IF values (i.e., weaker inhibitory effect) for microbially derived PLFA compared to terrestrially derived SRFA and NAFA confirm previously measured IF data at $\mathrm{pH}$ $8 .^{34}$

Regarding the $\mathrm{pH}$ dependence of the inhibitory effect, four out of eight TCs (ANI, 4MtA, DMA, and SCPD) with 2AN as a photosensitizer showed a decreasing IF with increasing $\mathrm{pH}$. For 4MA, SMX, and SD, there was either an increase in IF or no obvious trend with $\mathrm{pH}$. The results for the latter TCs appear to not support the initial hypothesis that IF decreases (i.e., inhibition increases) with increasing $\mathrm{pH}$, considering that the antioxidant capacity of DOMs (measured as electrondonating capacity, EDC) almost doubles by increasing the $\mathrm{pH}$ from 7 to $9 .{ }^{43}$ IF trends were similar for both 2AN and CBBP, except for 4MA. The data of 4-CNP, which show an almost constant inhibitory effect over the studied $\mathrm{pH}$ range (Figure $3 c$ ), could be explained by the high reduction potential (i.e., strongly oxidizing character) of the 4-cyanophenoxyl radical ( $1.12 \mathrm{~V}$, see Table 1$)$. This may cause a very efficient reduction of this radical by both undissociated and deprotonated phenolic antioxidant moieties of DOM, leading to re-formation of the parent compound and hence inhibited reaction. Furthermore, especially for 4MtA, but also for DMA and SD, some IF values $>1$ were observed in the lower $\mathrm{pH}$ range, meaning that for these TCs and these $\mathrm{pH}$ conditions an enhancement effect of DOM was dominant over a possible inhibitory effect. Analogous enhancements have been observed previously and attributed to the formation of oxidizing species resulting from the reaction of DOM with the primary oxidant, specifically, the triplet state of a model photosensitizer ${ }^{33,34}$ but also for the sulfate, radical which was studied separately. ${ }^{86}$ This enhancement effect could explain the unclear trends observed for System 2.

Transformation of TCs by DOM as a Photosensitizer in the Presence of Phenol as an Antioxidant (System 3). Experiments were performed using aniline as a TC, DOM isolates as photosensitizers, and phenol as an antioxidant in the $\mathrm{pH}$ range from 6 to 9. Their results are represented in terms of IF in Figure S17. While the inhibitory effect of phenol was almost absent at $\mathrm{pH} 6$ (i.e., $\mathrm{IF} \cong 1$ ), it was significant at higher $\mathrm{pH}$, with an increase in inhibition (i.e., decrease in IF) observed for PLFA and SRFA, and a $\mathrm{pH}$-independent IF for NAFA. The effect of phenol addition on IF was more pronounced for PLFA than for SRFA or NAFA, which can be ascribed to the lower intrinsic phenol content of PLFA ${ }^{32,50}$ and concurs with the results of previous studies performed at $\mathrm{pH}$ near $8 .^{35,37}$

Transformation of TCs in the Presence of 2Acetonaphthone as a Model Photosensitizer and Phenol as a Model Antioxidant (System 4). For this part of the study, four anilines (ANI, 4MA, 4MtA, and DMA) and three sulfonamides (SD, SMX, and SCPD) were tested as TCs (Figure S18). The IF of all anilines decreased with increasing $\mathrm{pH}$ up to $\mathrm{pH} 9$, in agreement with the basic hypothesis that the phenolate ion is a better inhibitor of these photosensitized reactions than the undissociated phenol. At $\mathrm{pH}$ 6, 4MA and DMA transformation was not inhibited, while for $4 \mathrm{MtA}$, even an enhanced reaction (IF > 1) is observed at $\mathrm{pH} 6$ and 7. At the highest $\mathrm{pH}$ of 11, a reversal in trend is observed for $4 \mathrm{MA}$ and $4 \mathrm{MtA}$, i.e., IF is higher compared to $\mathrm{pH}$ 10. An extended discussion of the behavior of the anilines including transformation data is given in the next subsection. For sulfonamides, there is no obvious $\mathrm{pH}$ trend. SD exhibited the lowest IF at circumneutral $\mathrm{pH}$ as observed with natural antioxidants, while IF for SMX decreased with increasing $\mathrm{pH}$.

For a rough comparison of the relative changes in IF with $\mathrm{pH}$ with phenol and the natural antioxidants SRFA, PLFA, and NAFA, the ratio of the corresponding IFs was calculated (i.e., $\mathrm{IF}_{\text {natural AO,pH }} / \mathrm{IF}_{\text {phenol,pH}}$, Figure S19). We note that such comparison needs to be interpreted carefully since antioxidant concentration and type are different. For 4MtA, SCPD, and $\mathrm{SD}$, except at $\mathrm{pH} 7$, the ratios are $\sim 1$ over the whole $\mathrm{pH}$ range. This confirms the qualitative observation from above that IF values behave similarly with changing $\mathrm{pH}$ in the presence of either natural or model antioxidants. IF ratios for ANI, 4MA, and DMA increase with $\mathrm{pH}$, indicating a relative increase of inhibition with increasing $\mathrm{pH}$ in systems with phenol as a model antioxidant. 
Correlation between the Inhibitory Effect and pHDependent Redox Potentials. In systems consisting of both a model photosensitizer and a model antioxidant (System 4), $\mathrm{pH}$-dependent redox potentials were used to rationalize the inhibitory effect across different TCs in the studied $\mathrm{pH}$ range. Both the model antioxidant phenol and the four aniline target compounds (ANI, 4MA, 4MtA, and DMA) have $\mathrm{pH}$ dependent redox potentials, which are represented in Figure $4 \mathrm{a}$. The one-electron reduction potential of the redox couple consisting of the phenoxyl radical (both protonated and neutral form) and the phenol (both molecular and deprotonated form) decreases linearly (slope of $-0.059 \mathrm{~V}$ per $\mathrm{pH}$ unit) with increasing $\mathrm{pH}$ from 0 to 10 , reaching a constant value of $0.79 \mathrm{~V}$ vs SHE above $\mathrm{pH} 10$ at which reduction of the radical to the phenolate is not coupled to proton uptake.

For the anilinyl radicals (protonated and neutral forms are considered), the one-electron reduction potentials decrease in the same way as for phenol in the $\mathrm{pH}$ range from 0 to the $\mathrm{p} K_{\mathrm{a}}$ values of the individual anilines (4.9-5.4), remain constant (i.e., $\mathrm{pH}$ independent) in the $\mathrm{pH}$ range between these values and the $\mathrm{p} K_{\mathrm{a}}$ values of the aniline radical cations, and then decrease linearly with $\mathrm{pH}$ (slope of $-0.059 \mathrm{~V}$ per $\mathrm{pH}$ unit) in the higher $\mathrm{pH}$ range. The only exception to this additional decrease in $E_{\text {red }}$ with $\mathrm{pH}$ is DMA, which maintains a constant reduction potential even at high $\mathrm{pH}$ since its radical cation does not deprotonate over the studied $\mathrm{pH}$ range. Except for $4 \mathrm{MtA}, E_{\text {red }}(\mathrm{pH})$ functions for anilinyl radicals, which for $0<$ $\mathrm{pH}<5$, are lower than the corresponding function for the phenoxyl radical, cross at some $\mathrm{pH}$ value the $E_{\text {red }}(\mathrm{pH})$ function of the latter, meaning that the oxidation of phenol by the anilinyl radicals (cationic or neutral forms) becomes thermodynamically favorable above this $\mathrm{pH}$. A second crossing of the reduction potentials of anilines and phenol occurs for ANI and 4MA at $\mathrm{pH}$ values well above the $\mathrm{p} K_{\mathrm{a}}$ of phenol, and the oxidation of phenol by the corresponding anilinyl radicals becomes thermodynamically unfavorable above these $\mathrm{pH}$ values.

To better illustrate the thermodynamics of these redox reactions, Figure $4 \mathrm{~b}$ shows the difference of reduction potential between each anilinyl and phenoxyl radicals (i.e., $\Delta E_{\text {red }}=$ $\left.E_{\text {red,anilinyl }}-E_{\text {red,phenoxyl }}\right)$. The diagram also contains data on the inhibitory effect, expressed as inverse inhibition factor (1/IF: high $1 /$ IF corresponds to high inhibitory effect) for the four anilines. The magnitude of the inhibitory effect clearly correlates with increasing $\Delta E_{\text {red }}$ in the order of ANI $>4 \mathrm{MA}$ $>$ DMA > 4MtA and follows, for each of the anilines, the $\mathrm{pH}$ dependence of $\Delta E_{\text {red. }}$. It can be concluded that the inhibition is determined by the $\mathrm{pH}$ (and speciation)-dependent reduction potential difference between the phenoxyl/phenol and the anilinyl/aniline couples. Interestingly, inhibition (1/IF > 1) of aniline oxidation was observed even for thermodynamically unfavorable conditions, i.e., negative $\Delta E_{\text {red. }}$ For $\Delta E_{\text {red }}<0 \mathrm{~V}$, the reaction rate constant for the reduction should be smaller and eventually become insignificant compared to conditions with positive $\Delta E_{\text {red }}$. Simultaneously, for $\Delta E_{\text {red }}<0 \mathrm{~V}$, the back reaction, i.e., the oxidation of the aniline via the phenoxyl radical is expected to be faster than the forward reaction.

To explain the observed IF under these conditions, scavenging of the phenoxyl radical, which outcompetes the back reaction, must be assumed. Possible scavengers of the phenoxyl radical include the phenoxyl radical itself, superoxide, and phenol, ${ }^{87}$ the latter reaction leading to radical adducts. ${ }^{88}$
The aforementioned thermodynamic considerations also offer arguments to explain the reaction enhancement (IF > 1) observed for 4MtA at $\mathrm{pH} 6$ and 7 (see the preceding subsection). Phenoxyl radicals, which may be formed by oxidation of phenol by the excited triplet state of 2-AN, may cause an effective oxidation of $4 \mathrm{MtA}$, since this reaction is the most favorable among the ones considered (see Figure 4b). In turn, the anilinyl radicals of $4 \mathrm{MtA}$ cannot be reduced by phenol. As a result, the oxidation of $4 \mathrm{MtA}$ by phenoxyl radicals prevails, causing an enhancement of the photosensitized transformation of 4MtA.

The $\Delta E_{\text {red }}$ vs $\mathrm{pH}$ trends presented in Figure $4 \mathrm{~b}$, which exhibit maxima in correspondence of $1 /$ IF maxima, can explain qualitatively the occurrence of the minima in IF (corresponding to maxima in 1/IF) observed in several cases for System 2 data (see Figure 3). This observation can be extended by analogy to the minima in CIF observed for System 1 data (see Figure 2). The fact that, for DOM acting as an antioxidant, the minima in IF or CIF occur at lower $\mathrm{pH}$ than for phenol might be due to the lower $\mathrm{pK}_{\mathrm{a}}$ of phenolic moieties of $\mathrm{DOM}^{32}$ compared to phenol.

For sulfonamides, predictions about IF based on $\Delta E_{\text {red }}$ can only be made at the level of guesses due to the missing knowledge on the reduction potentials of their radicals and the complex speciation behavior of the latter. ${ }^{80}$ Radicals of the anilinium type would have a higher one-electron reduction potential (e.g., $\sim 1.3 \mathrm{~V}$ vs SHE for SD) ${ }^{89}$ and are also expected to have lower $\mathrm{p} K_{\mathrm{a}}^{*}$ values (e.g., $\sim 6.3$ estimated for $\mathrm{SD}$ using quantum chemical computations $)^{80}$ than the corresponding radicals of the anilines studied here. The higher reduction potentials can explain generally the lower IF values (more efficient inhibition) observed, especially in the lower $\mathrm{pH}$ range, for the sulfonamides compared to the anilines. Lower $\mathrm{p} K_{\mathrm{a}}^{*}$ values would explain why the IF minima and onsets to increasing IF would occur at lower $\mathrm{pH}$ for the sulfonamides compared to the anilines.

\section{ENVIRONMENTAL IMPLICATIONS}

This study presents the first comprehensive collection of kinetic data on the $\mathrm{pH}$ dependence of the photosensitized transformation of aromatic amines under conditions relevant to sunlit surface waters. Pseudo-first-order rate constants for aromatic amines photosensitized by PLFA and SRFA, as surrogates of dissolved organic matter present in surface waters, varied depending on the specific target compound by a factor of up to $\sim 7$ in the $6-11 \mathrm{pH}$ range. For the realistic situation encountered in most freshwaters buffered by bicarbonate/carbonate, $\mathrm{pH}$ varies between 7 and 9, and the $\mathrm{pH}$-induced variability of pseudo-first-order rate constants reduces significantly for several of the studied compounds. However, at the smaller range of environmentally occurring $\mathrm{pH}$, the maximum observed variability factor of $\sim 5$ remains high. Therefore, to accurately predict the fate of aromatic amines in surface waters, investigations on the $\mathrm{pH}$ dependence of their photosensitized transformation may be required.

It is generally assumed that the transformation kinetics and abatement of contaminants in the aquatic environment can be described in terms of their speciation using corresponding rate constants (independent of the water matrix composition) for each species and, when applicable, the steady-state concentration of aquatic reactive species (such as ${ }^{3} \mathrm{DOM}^{*},{ }^{1} \mathrm{O}_{2}$, or the hydroxyl radical). However, this approach has limitations, and the present study has highlighted, for the studied aromatic 
amines, the existence of a $\mathrm{pH}$-dependent photosensitized transformation kinetics beyond a simple speciation effect.

The hypothesis of an increased inhibitory effect of DOM on photosensitized transformation of aromatic amines at higher $\mathrm{pH}$ could not be confirmed for several studied compounds. A possible explanation for this failure is the important increase in the efficiency of photosensitized transformation with increasing $\mathrm{pH}$, observed for several compounds. Moreover, other not yet well understood compound-specific effects, such as protonation equilibria, lifetimes, and reactions (possibly addition to and reduction by superoxide radical anion, and addition to DOM) of the radicals derived from the oxidation of the compounds, might affect transformation rates of these compounds. Beyond oxidations induced by excited triplet states, the inhibitory effect of DOM may also occur for the radical-induced reactions of organic contaminants, as recently shown for the sulfate radical ${ }^{86}$ produced by photolysis of persulfate. For the latter system, a clearer response of the inhibitory effect of DOM with increasing $\mathrm{pH}$ is expected due to the absence of significant superoxide sources that would compete with DOM-induced inhibition.

\section{ASSOCIATED CONTENT}

\section{SI Supporting Information}

The Supporting Information is available free of charge at https://pubs.acs.org/doi/10.1021/acs.est.1c03301.

$E_{\text {red }}$ and $\Delta E_{\text {red }}$ calculations (XLSX)

Chemicals used, preparation of stock solutions, analytical details, discussing direct phototransformation of target compounds, effects of changes in absorption spectra, role of singlet oxygen and superoxide, relationships of redox potentials of phenol and anilines with $\mathrm{pH}$ (Texts S1-S6); HPLC analysis parameters, direct phototransformation rates, measured and corrected photosensitized transformation rates, absorption coefficients of photosensitizers, including for DOMs, and light attenuation factors of experimental solutions (Tables S1-S14); and UV-vis absorption spectra of photosensitizers, DOMs, and target compounds, depletion kinetics of target compounds and phenol, and phototransformation rates with model sensitizers in the presence of model and natural antioxidants (Figures S1S19) (PDF)

\section{AUTHOR INFORMATION}

\section{Corresponding Authors}

Jannis Wenk - Eawag, Swiss Federal Institute of Aquatic

Science and Technology, CH-8600 Dübendorf, Switzerland; Institute of Biogeochemistry and Pollutant Dynamics, ETH Zürich, CH-8092 Zürich, Switzerland; Department of Chemical Engineering and Water Innovation \& Research Centre (WIRC), University of Bath, Bath BA2 7AY, United Kingdom; (1) orcid.org/0000-0001-9182-0407;

Phone: +44-1225-383246; Email: j.h.wenk@bath.ac.uk

Silvio Canonica - Eawag, Swiss Federal Institute of Aquatic Science and Technology, CH-8600 Dübendorf, Switzerland; (1) orcid.org/0000-0001-6848-947X; Phone: +41-58-7655453; Email: silvio.canonica@eawag.ch; Fax: +41-58-7655210

\section{Authors}

Cornelia Graf - Institute of Biogeochemistry and Pollutant Dynamics, ETH Zürich, CH-8092 Zürich, Switzerland; INFRAS Research and Consulting, CH-3012 Berne, Switzerland

Michael Aeschbacher - Institute of Biogeochemistry and Pollutant Dynamics, ETH Zürich, CH-8092 Zürich, Switzerland

Michael Sander - Institute of Biogeochemistry and Pollutant Dynamics, ETH Zürich, CH-8092 Zürich, Switzerland; (1) orcid.org/0000-0003-3383-2041

Complete contact information is available at: https://pubs.acs.org/10.1021/acs.est.1c03301

\section{Notes}

The authors declare no competing financial interest.

\section{ACKNOWLEDGMENTS}

This work was funded by the Swiss National Science Foundation (Projects 200021-117911 and 200020-134801). The authors thank Jeremy Schälchli and Alessandro Piazzoli for experimental assistance, Hans-Ulrich Laubscher and Lisa Salhi for technical support, and five anonymous reviewers who helped to improve this manuscript.

\section{REFERENCES}

(1) Lundeen, R. A.; Janssen, E. M. L.; Chu, C.; McNeill, K. Environmental photochemistry of amino acids, peptides and proteins. Chimia 2014, 68, 812-824.

(2) Burrows, H. D.; Canle L, M.; Santaballa, J. A.; Steenken, S. Reaction pathways and mechanisms of photodegradation of pesticides. J. Photochem. Photobiol., B 2002, 67, 71-108.

(3) Garrett, R. M.; Pickering, I. J.; Haith, C. E.; Prince, R. C. Photooxidation of crude oils. Environ. Sci. Technol. 1998, 32, 37193723.

(4) Liu, J.; Zhang, X.; Li, Y. Photoconversion of Chlorinated Saline Wastewater DBPs in Receiving Seawater is Overall a Detoxification Process. Environ. Sci. Technol. 2017, 51, 58-67.

(5) Liu, J.; Zhang, X.; Li, Y.; Li, W.; Hang, C.; Sharma, V. K. Phototransformation of halophenolic disinfection byproducts in receiving seawater: Kinetics, products, and toxicity. Water Res. 2019, 150, 68-76.

(6) Hedges, J. I.; Eglinton, G.; Hatcher, P. G.; Kirchman, D. L.; Arnosti, C.; Derenne, S.; Evershed, R. P.; Kögel-Knabner, I.; De Leeuw, J. W.; Littke, R.; Michaelis, W.; Rullkötter, J. The molecularlyuncharacterized component of nonliving organic matter in natural environments. Org. Geochem. 2000, 31, 945-958.

(7) McDonald, S.; Bishop, A. G.; Prenzler, P. D.; Robards, K. Analytical chemistry of freshwater humic substances. Anal. Chim. Acta 2004, 527, 105-124.

(8) Thurman, E. M. Organic Geochemistry of Natural Waters; Springer Science \& Business Media, 1985.

(9) Remucal, C. K. The role of indirect photochemical degradation in the environmental fate of pesticides: A review. Environ. Sci.: Processes Impacts 2014, 16, 628-653.

(10) Boreen, A. L.; Arnold, W. A.; McNeill, K. Photodegradation of pharmaceuticals in the aquatic environment: A review. Aquat. Sci. 2003, 65, 320-341.

(11) Vione, D.; Minella, M.; Maurino, V.; Minero, C. Indirect photochemistry in sunlit surface waters: Photoinduced production of reactive transient species. Chem. - Eur. J. 2014, 20, 10590-10606.

(12) Mattle, M. J.; Vione, D.; Kohn, T. Conceptual model and experimental framework to determine the contributions of direct and indirect photoreactions to the solar disinfection of MS2, phiX174, and adenovirus. Environ. Sci. Technol. 2015, 49, 334-342. 
(13) Maraccini, P. A.; Wenk, J.; Boehm, A. B. Exogenous indirect photoinactivation of bacterial pathogens and indicators in water with natural and synthetic photosensitizers in simulated sunlight with reduced UVB. J. Appl. Microbiol. 2016, 121, 587-597.

(14) Maraccini, P. A.; Wenk, J.; Boehm, A. B. Photoinactivation of Eight Health-Relevant Bacterial Species: Determining the Importance of the Exogenous Indirect Mechanism. Environ. Sci. Technol. 2016, 50, 5050-5059.

(15) Helms, J. R.; Stubbins, A.; Ritchie, J. D.; Minor, E. C.; Kieber, D. J.; Mopper, K. Absorption spectral slopes and slope ratios as indicators of molecular weight, source, and photobleaching of chromophoric dissolved organic matter. Limnol. Oceanogr. 2008, 53, 955-969.

(16) Sharpless, C. M.; Aeschbacher, M.; Page, S. E.; Wenk, J.; Sander, M.; McNeill, K. Photooxidation-induced changes in optical, electrochemical, and photochemical properties of humic substances. Environ. Sci. Technol. 2014, 48, 2688-2696.

(17) Del Vecchio, R.; Blough, N. V. Photobleaching of chromophoric dissolved organic matter in natural waters: kinetics and modeling. Mar. Chem. 2002, 78, 231-253.

(18) Timko, S. A.; Gonsior, M.; Cooper, W. J. Influence of pH on fluorescent dissolved organic matter photo-degradation. Water Res. 2015, 85, 266-274.

(19) Marchisio, A.; Minella, M.; Maurino, V.; Minero, C.; Vione, D. Photogeneration of reactive transient species upon irradiation of natural water samples: Formation quantum yields in different spectral intervals, and implications for the photochemistry of surface waters. Water Res. 2015, 73, 145-156.

(20) Zeng, T.; Arnold, W. A. Pesticide photolysis in prairie potholes: Probing photosensitized processes. Environ. Sci. Technol. 2013, 47, 6735-6745.

(21) Richard, C.; Canonica, S. Aquatic Phototransformation of Organic Contaminants Induced by Coloured Dissolved Natural Organic Matter. In Environmental Photochemistry Part II; Boule, P.; Bahnemann, D. W.; Robertson, P. K. J., Eds.; Springer: Berlin, 2005; Vol. 2M, pp 299-323.

(22) Cory, R. M.; Cotner, J. B.; McNeill, K. Quantifying Interactions between Singlet Oxygen and Aquatic Fulvic Acids. Environ. Sci. Technol. 2009, 43, 718-723.

(23) Frimmel, F. H. Photochemical aspects related to humic substances. Environ. Int. 1994, 20, 373-385.

(24) Page, S. E.; Logan, J. R.; Cory, R. M.; McNeill, K. Evidence for dissolved organic matter as the primary source and sink of photochemically produced hydroxyl radical in arctic surface waters. Environ. Sci.: Processes Impacts 2014, 16, 807-822.

(25) Dalrymple, R. M.; Carfagno, A. K.; Sharpless, C. M. Correlations between dissolved organic matter optical properties and quantum yields of singlet oxygen and hydrogen peroxide. Environ. Sci. Technol. 2010, 44, 5824-5829.

(26) Canonica, S.; Kohn, T.; Mac, M.; Real, F. J.; Wirz, J.; Von Gunten, U. Photosensitizer method to determine rate constants for the reaction of carbonate radical with organic compounds. Environ. Sci. Technol. 2005, 39, 9182-9188.

(27) Canonica, S. Oxidation of aquatic organic contaminants induced by excited triplet states. Chimia 2007, 61, 641-644.

(28) Boreen, A. L.; Arnold, W. A.; McNeill, K. Triplet-sensitized photodegradation of sulfa drugs containing six-membered heterocyclic groups: Identification of an $\mathrm{SO} 2$ extrusion photoproduct. Environ. Sci. Technol. 2005, 39, 3630-3638.

(29) McNeill, K.; Canonica, S. Triplet state dissolved organic matter in aquatic photochemistry: Reaction mechanisms, substrate scope, and photophysical properties. Environ. Sci.: Processes Impacts 2016, 18, 1381-1399.

(30) Klán, P.; Wirz, J. Photochemistry of Organic Compounds: From Concepts to Practice; John Wiley \& Sons, 2009; pp 1-563.

(31) Malcolm, R. L. The uniqueness of humic substances in each of soil, stream and marine environments. Anal. Chim. Acta 1990, 232, 19-30.
(32) Ritchie, J. D.; Perdue, E. M. Proton-binding study of standard and reference fulvic acids, humic acids, and natural organic matter. Geochim. Cosmochim. Acta 2003, 67, 85-96.

(33) Canonica, S.; Laubscher, H.-U. Inhibitory effect of dissolved organic matter on triplet-induced oxidation of aquatic contaminants. Photochem. Photobiol. Sci. 2008, 7, 547-551.

(34) Wenk, J.; von Gunten, U.; Canonica, S. Effect of dissolved organic matter on the transformation of contaminants induced by excited triplet states and the hydroxyl radical. Environ. Sci. Technol. 2011, 45, 1334-1340.

(35) Wenk, J.; Canonica, S. Phenolic antioxidants inhibit the tripletinduced transformation of anilines and sulfonamide antibiotics in aqueous solution. Environ. Sci. Technol. 2012, 46, 5455-5462.

(36) Wenk, J.; Aeschbacher, M.; Sander, M.; Gunten, U. V.; Canonica, S. Photosensitizing and Inhibitory Effects of Ozonated Dissolved Organic Matter on Triplet-Induced Contaminant Transformation. Environ. Sci. Technol. 2015, 49, 8541-8549.

(37) Bahnmüller, S.; von Gunten, U.; Canonica, S. Sunlight-induced transformation of sulfadiazine and sulfamethoxazole in surface waters and wastewater effluents. Water Res. 2014, 57, 183-192.

(38) Wenk, J.; Aeschbacher, M.; Salhi, E.; Canonica, S.; von Gunten, U.; Sander, M. Chemical oxidation of dissolved organic matter by chlorine dioxide, chlorine, and ozone: effects on its optical and antioxidant properties. Environ. Sci. Technol. 2013, 47, 11147-11156.

(39) Janssen, E. M. L.; Erickson, P. R.; McNeill, K. Dual roles of dissolved organic matter as sensitizer and quencher in the photooxidation of tryptophan. Environ. Sci. Technol. 2014, 48, 4916-4924.

(40) Leresche, F.; Von Gunten, U.; Canonica, S. Probing the Photosensitizing and Inhibitory Effects of Dissolved Organic Matter by Using N,N-dimethyl-4-cyanoaniline (DMABN). Environ. Sci. Technol. 2016, 50, 10997-11007.

(41) Davis, C. A.; Erickson, P. R.; McNeill, K.; Janssen, E. M. L. Environmental photochemistry of fenamate NSAIDs and their radical intermediates. Environ. Sci.: Processes Impacts 2017, 19, 656-665.

(42) Vione, D.; Fabbri, D.; Minella, M.; Canonica, S. Effects of the antioxidant moieties of dissolved organic matter on triplet-sensitized phototransformation processes: Implications for the photochemical modeling of sulfadiazine. Water Res. 2018, 128, 38-48.

(43) Aeschbacher, M.; Graf, C.; Schwarzenbach, R. P.; Sander, M. Antioxidant Properties of Humic Substances. Environ. Sci. Technol. 2012, 46, 4916-4925.

(44) Walpen, N.; Getzinger, G. J.; Schroth, M. H.; Sander, M. Electron-Donating Phenolic and Electron-Accepting Quinone Moieties in Peat Dissolved Organic Matter: Quantities and Redox Transformations in the Context of Peat Biogeochemistry. Environ. Sci. Technol. 2018, 52, 5236-5245.

(45) Wenk, J.; Eustis, S. N.; McNeill, K.; Canonica, S. Quenching of excited triplet states by dissolved natural organic matter. Environ. Sci. Technol. 2013, 47, 12802-12810.

(46) Qu, S.; Kolodziej, E. P.; Long, S. A.; Gloer, J. B.; Patterson, E. V.; Baltrusaitis, J.; Jones, G. D.; Benchetler, P. V.; Cole, E. A.; Kimbrough, K. C.; Tarnoff, M. D.; Cwiertny, D. M. Product-to-parent reversion of trenbolone: Unrecognized risks for endocrine disruption. Science 2013, 342, 347-351.

(47) Baltrusaitis, J.; Patterson, E. V.; O'Connor, M.; Qu, S.; Kolodziej, E. P.; Cwiertny, D. M. Reversible Photohydration of Trenbolone Acetate Metabolites: Mechanistic Understanding of Product-to-Parent Reversion through Complementary Experimental and Theoretical Approaches. Environ. Sci. Technol. 2016, 50, 67536761.

(48) Canonica, S.; Hellrung, B.; Müller, P.; Wirz, J. Aqueous oxidation of phenylurea herbicides by triplet aromatic ketones. Environ. Sci. Technol. 2006, 40, 6636-6641.

(49) Yuan, C.; Chakraborty, M.; Canonica, S.; Weavers, L. K.; Hadad, C. M.; Chin, Y. P. Isoproturon Reappearance after Photosensitized Degradation in the Presence of Triplet Ketones or Fulvic Acids. Environ. Sci. Technol. 2016, 50, 12250-12257.

(50) Driver, S. J.; Perdue, E. M. Acidic Functional Groups of Suwannee River Natural Organic Matter, Humic Acids, and Fulvic 
Acids. In Advances in the Physicochemical Characterization of Dissolved Organic Matter: Impact on Natural and Engineered Systems; American Chemical Society, 2014; Vol. 1160, pp 75-86.

(51) Canonica, S.; Hellrung, B.; Wirz, J. Oxidation of phenols by triplet aromatic ketones in aqueous solution. J. Phys. Chem. A 2000, $104,1226-1232$.

(52) Qin, L.; Tripathi, G. N. R.; Schüler, R. H. Radiation Chemical Studies of the Oxidation of Aniline in Aqueous Solution. Z. Naturforsch. A 1985, 40, 1026-1039.

(53) Jonsson, M.; Lind, J.; Eriksen, T. E.; Merényi, G. Redox and Acidity Properties of 4-Substituted Aniline Radical Cations in Water. J. Am. Chem. Soc. 1994, 116, 1423-1427.

(54) Dombrowski, G. W.; Dinnocenzo, J. P.; Zielinski, P. A.; Farid, S.; Wosinska, Z. M.; Gould, I. R. Efficient unimolecular deprotonation of aniline radical cations. J. Org. Chem. 2005, 70, 3791-3800.

(55) Prasse, C.; Wenk, J.; Jasper, J. T.; Ternes, T. A.; Sedlak, D. L. Co-occurrence of Photochemical and Microbiological Transformation Processes in Open-Water Unit Process Wetlands. Environ. Sci. Technol. 2015, 49, 14136-14145.

(56) Jasper, J. T.; Sedlak, D. L. Phototransformation of wastewaterderived trace organic contaminants in open-water unit process treatment wetlands. Environ. Sci. Technol. 2013, 47, 10781-10790.

(57) Zhang, Y. N.; Zhao, J.; Zhou, Y.; Qu, J.; Chen, J.; Li, C.; Qin, W.; Zhao, Y.; Peijnenburg, W. J. G. M. Combined effects of dissolved organic matter, $\mathrm{pH}$, ionic strength and halides on photodegradation of oxytetracycline in simulated estuarine waters. Environ. Sci.: Processes Impacts 2019, 21, 155-162.

(58) Patel-Sorrentino, N.; Mounier, S.; Benaim, J. Y. Excitationemission fluorescence matrix to study $\mathrm{pH}$ influence on organic matter fluorescence in the Amazon basin rivers. Water Res. 2002, 36, 25712581.

(59) Panneer Selvam, B.; Lapierre, J. F.; Soares, A. R. A.; Bastviken, D.; Karlsson, J.; Berggren, M. Photo-reactivity of dissolved organic carbon in the freshwater continuum. Aquat. Sci. 2019, 81, No. 57.

(60) Pace, M. L.; Reche, I.; Cole, J. J.; Fernández-Barbero, A.; Mazuecos, I. P.; Prairie, Y. T. pH change induces shifts in the size and light absorption of dissolved organic matter. Biogeochemistry 2012, 108, 109-118.

(61) Dryer, D. J.; Korshin, G. V.; Fabbricino, M. In situ examination of the protonation behavior of fulvic acids using differential absorbance spectroscopy. Environ. Sci. Technol. 2008, 42, 6644-6649.

(62) Song, G.; Li, Y.; Hu, S.; Li, G.; Zhao, R.; Sun, X.; Xie, H. Photobleaching of chromophoric dissolved organic matter (CDOM) in the Yangtze River estuary kinetics and effects of temperature, $\mathrm{pH}$, and salinity. Environ. Sci.: Processes Impacts 2017, 19, 861-873.

(63) Canonica, S.; Jans, U.; Stemmler, K.; Hoigné, J. Transformation kinetics of phenols in water - Photosensitation by dissolved natural organic matter and aromatic ketones. Environ. Sci. Technol. 1995, 29, $1822-1831$.

(64) Canonica, S.; Freiburghaus, M. Electron-rich phenols for probing the photochemical reactivity of freshwaters. Environ. Sci. Technol. 2001, 35, 690-695.

(65) Kaur, R.; Anastasio, C. First Measurements of Organic Triplet Excited States in Atmospheric Waters. Environ. Sci. Technol. 2018, 52, $5218-5226$.

(66) Yuan, C.; Sleighter, R. L.; Weavers, L. K.; Hatcher, P. G.; Chin, Y. P. Fast Photomineralization of Dissolved Organic Matter in Acid Mine Drainage Impacted Waters. Environ. Sci. Technol. 2019, 53, 6273-6281.

(67) McKnight, D. M.; Boyer, E. W.; Westerhoff, P. K.; Doran, P. T.; Kulbe, T.; Andersen, D. T. Spectrofluorometric characterization of dissolved organic matter for indication of precursor organic material and aromaticity. Limnol. Oceanogr. 2001, 46, 38-48.

(68) Petrie, B.; Barden, R.; Kasprzyk-Hordern, B. A review on emerging contaminants in wastewaters and the environment: Current knowledge, understudied areas and recommendations for future monitoring. Water Res. 2015, 72, 3-27.

(69) Zoumpouli, G. A.; Siqueira Souza, F.; Petrie, B.; Féris, L. A.; Kasprzyk-Hordern, B.; Wenk, J. Simultaneous ozonation of 90 organic micropollutants including illicit drugs and their metabolites in different water matrices. Environ. Sci.: Water Res. Technol. 2020, 6, 2465-2478.

(70) Schwarzenbach, R. P.; Gschwend, P. M.; Imboden, D. M. Environmental Organic Chemistry, 3rd ed.; Wiley, 2016; p 1026.

(71) Kergoat, L.; Besse-Hoggan, P.; Leremboure, M.; Beguet, J.; Devers, M.; Martin-Laurent, F.; Masson, M.; Morin, S.; Roinat, A.; Pesce, S.; Bonnineau, C. Environmental Concentrations of Sulfonamides Can Alter Bacterial Structure and Induce Diatom Deformities in Freshwater Biofilm Communities. Front. Microbiol. 2021, 12, No. 643719.

(72) Anastasio, C.; Faust, B. C.; Rao, C. J. Aromatic carbonyl compounds as aqueous-phase photochemical sources of hydrogen peroxide in acidic sulfate aerosols, fogs, and clouds. 1. Non-phenolic methoxybenzaldehydes and methoxyacetophenones with reductants (phenols). Environ. Sci. Technol. 1997, 31, 218-232.

(73) Gorman, A. A.; Parekh, C. T.; Rodgers, M. A. J.; Smith, P. G. The quenching of the triplet states of aromatic carbonyl compounds by triethylamine: Solvent effects on correlations with the function $\{3 \Delta \mathrm{E}<\mathrm{inf}>0, \mathrm{o}</$ inf $>+\mathrm{E}(\mathrm{A}-/ \mathrm{A})\}$. J. Photochem. 1978, 9, 11-17.

(74) Loeff, I.; Rabani, J.; Treinin, A.; Linschitz, H. Charge Transfer and Reactivity of $\mathrm{n} \pi^{*}$ and $\pi \pi^{*}$ Organic Triplets, Including Anthraquinonesulfonates, in Interactions with Inorganic Anions: A Comparative Study Based on Classical Marcus Theory. J. Am. Chem. Soc. 1993, 115, 8933-8942.

(75) CRC Handbook of Chemistry and Physics, 101st ed.; Rumble, J., Ed.; CRC Press Taylor \& Francis, 2020.

(76) Inbar, S.; Linschitz, H.; Cohen, S. G. Quenching, Radical Formation, and Disproportionation in the Photoreduction of 4Carboxybenzophenone by 4-Carboxybenzhydrol, Hydrazine, and Hydrazinium Ion. J. Am. Chem. Soc. 1981, 103, 7323-7328.

(77) Hurley, J. K.; Linschitz, H.; Treinin, A. Interaction of halide and pseudohalide ions with triplet benzophenone-4-carboxylate: kinetics and radical yields. J. Phys. Chem. A 1988, 92, 5151-5159.

(78) Huie, R. E.; Neta, P. Kinetics of one-electron transfer reactions involving $\mathrm{ClO} 2$ and NO2. J. Phys. Chem. B 1986, 90, 1193-1198.

(79) Boreen, A. L.; Arnold, W. A.; McNeill, K. Photochemical fate of sulfa drugs in then aquatic environment: Sulfa drugs containing fivemembered heterocyclic groups. Environ. Sci. Technol. 2004, 38, 39333940.

(80) Tentscher, P. R.; Eustis, S. N.; McNeill, K.; Arey, J. S. Aqueous oxidation of sulfonamide antibiotics: Aromatic nucleophilic substitution of an aniline radical cation. Chem. - Eur. J. 2013, 19, 1121611223.

(81) Dixon, W. T.; Murphy, D. Determination of the acidity constants of some phenol radical cations by means of electron spin resonance. J. Chem. Soc., Faraday Trans. 2 1976, 72, 1221-1230.

(82) Lind, J.; Shen, X.; Eriksen, T. E.; Merényi, G. The OneElectron Reduction Potential of 4-Substituted Phenoxyl Radicals in Water. J. Am. Chem. Soc. 1990, 112, 479-482.

(83) Jovanovic, S. V.; Tosic, M.; Simic, M. G. Use of the Hammett correlation and $\sigma+$ for calculation of one-electron redox potentials of antioxidants. J. Phys. Chem. E 1991, 95, 10824-10827.

(84) International Humic Substances Society (IHSS). Acidic Functional Groups of IHSS Samples. http://humic-substances.org/ acidic-functional-groups-of-ihss-samples/ (accessed 05/02/2021).

(85) Fukushima, M.; Tatsumi, K.; Morimoto, K. The fate of aniline after a photo-Fenton reaction in an aqueous system containing iron(III), humic acid, and hydrogen peroxide. Environ. Sci. Technol. 2000, 34, 2006-2013.

(86) Canonica, S.; Schönenberger, U. Inhibitory Effect of Dissolved Organic Matter on the Transformation of Selected Anilines and Sulfonamide Antibiotics Induced by the Sulfate Radical. Environ. Sci. Technol. 2019, 53, 11783-11791.

(87) Neta, P.; Grodkowski, J. Rate constants for reactions of phenoxyl radicals in solution. J. Phys. Chem. Ref. Data 2005, 34, 109199. 
(88) Das, T. N. Oxidation of phenol in aqueous acid: Characterization and reactions of radical cations vis-à-vis the phenoxyl radical. J. Phys. Chem. A 2005, 109, 3344-3351.

(89) Leresche, F.; Ludvíková, L.; Heger, D.; Von Gunten, U.; Canonica, S. Quenching of an Aniline Radical Cation by Dissolved Organic Matter and Phenols: A Laser Flash Photolysis Study. Environ. Sci. Technol. 2020, 54, 15057-15065.

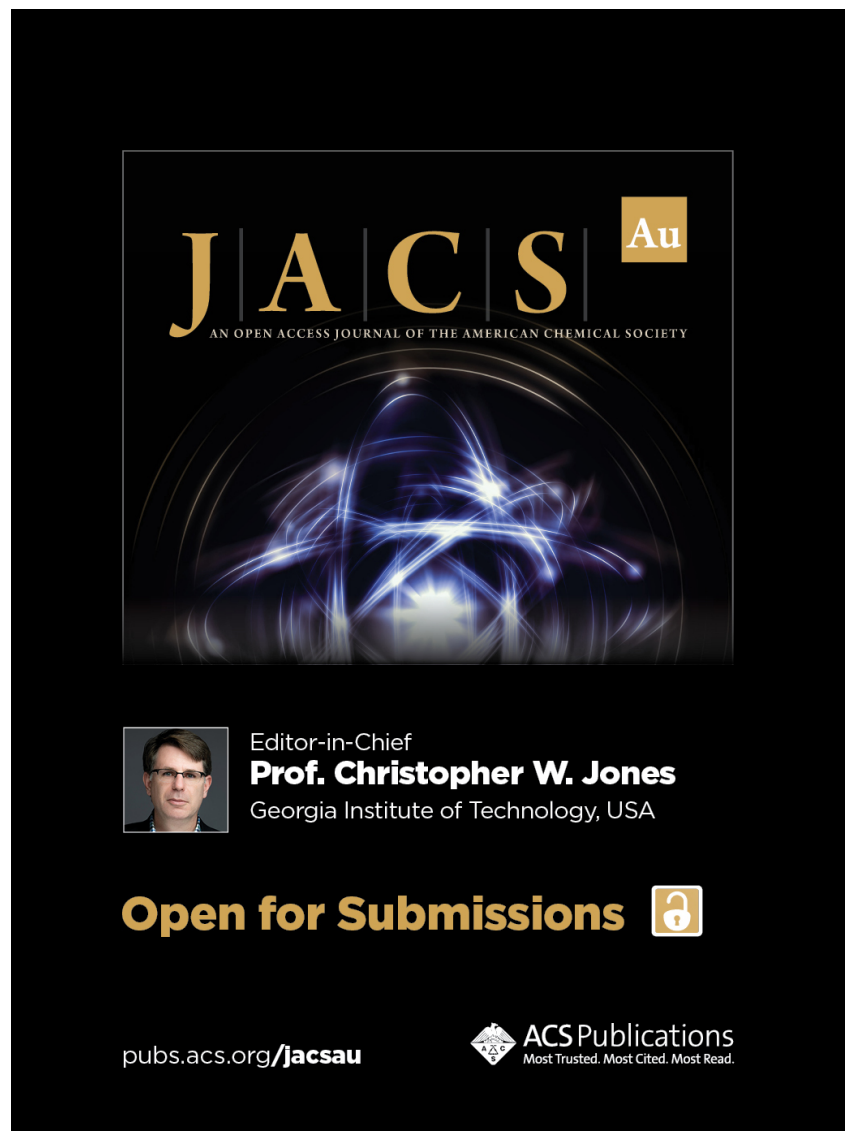

